\title{
Institutional Functions as a Theoretical Nexus and Measurement Target in Sociology of Education
}

\author{
Funciones institucionales como nexo teórico \\ y objetivo de medición en sociología de la educación
}

\section{Alexander Osipov ${ }^{1}$}

\begin{abstract}
The paper is devoted to methodological aspects of the study of institutional functions of education as one of the basic theoretical constructs of contemporary sociology of education. The author argues that the elaboration into the function problem also provides a direction for social-practical outputs of this branch of sociology, conceptual ground for its own theoretical, revitalizing its connection with general sociology. Without such elaboration, the author assumes, most of theoretical and empirical studies and measurements conducted by sociologists are doomed to thematic fragmentation, have slim chances to contribute to a shared sociological vision of education, delineate the area of institutional responsibility of education in society, improve educational politics, resist the neoliberal «Trojan horses» in education. The author brings a set of criteria to define the institutional functions of education, including the empirical measurability of each function, and a hypothetical model of functions detailed by four major areas of society: economic, social, cultural and political.
\end{abstract}

Key words

Education, institutional functions, criteria of definition, sociology.

\section{Resumen}

El presente texto aborda aspectos metodológicos del estudio de las funciones institucionales de la educación como uno de los constructos teóricos fundamentales de la sociología contemporánea de la educación. El autor sostiene que la reflexión sobre el problema de la función proporciona además una dirección para resultados sociales prácticos de este campo de la sociología, revitalizando su conexión con la sociología general. Sin tal elaboración, a juicio del autor, buena parte de los estudios teóricos y empíricos llevados a cabo por los sociólogos están condenados a la fragmentación temática, y tienen pocas ocasiones de contribuir a una visión sociológica compartida de la sociología de la educación, a una definición del área de la responsabilidad institucional de la educación en la sociedad, a una mejora de la política educativa, a una resistencia de «los caballos de Troya» institucionales en educación. El autor presenta un conjunto de criterios para definir las funciones institucionales de la educación, incluyendo la mensurabilidad empírica de cada función, y un modelo hipotético de funciones detalladas por cuatro áreas principales en la sociedad: económica, social, cultural y política.

\section{Palabras clave}

Educación, funciones institucionales, criterios de definición, sociología. 


\section{Concepts of functions-nexus of the sociology of education}

In the early $21^{\text {st }}$ century, the sociology of education became the most popular area of sociology in the world. But the area's leading experts are now speaking openly about the methodological, conceptual and political factors slowing and even halting its development in their respective countries (Osipov et al., 2013). Russian scholars are also writing about «working on the mistakes» in the field and advancing a list of its priorities upon whose achievement, they believe, it can become helpful in formulating a strategy and concrete solutions in educational policy.

In our opinion, the weakness of today's sociology of education in Russia and around the world is largely associated with the unpreparedness of scholars to solve the threshold problems which, firstly, form the theoretical carcass of this scientific field, and secondly, ensure its greatest-possible socially-practical return. Indeed, this science has thus far failed to prove that it is essential to society, to the administration of the education system.

\section{Concept of functions - nexus of the sociology of education}

The main and most difficult threshold was outlined by the classics of sociology and focused on the problem of the functions of education as a social institution. The centerpiece of this problem in the subject area of the sociology of education is not as clear for many scholars. In general sociology and the different branches of sociological theory, the problem of institutional functions has been posited with less thoroughness than other, more peripheral and emergent concerns (education accessibility, satisfaction with the education one receives, values-based attitude towards education, etc.). This problem is all but ignored in debates on the efficacy of education policy or the prospects of particular education systems (Antikainen et al., 2011). It is often perceived as an attribute of the long-since repudiated functionalism. But is it really possible to turn away from this problem if sociology itself endeavors to identify sustainable links between major phenomena and organizations in society? And if sociology withdraws into the shifting structures of the signs, metaphors, identities, networks and practices of everyday life, will it not run itself ragged in an endless circle without making any discernable progress for the theory and system of education? Thus, insofar as it is impossible to expel the problem of institutional functions from the framework of sociology, we shall briefly endeavor to return to its sources.

Durkheim wrote that education, as the organized («methodical») socialization of individuals, ensures the homogenization of society. He ascribed to functions the sense of sustained activity aiming the longterm impact of this institution towards the greater benefit of the entire social system. But he has not marked any theoretical boundaries of the category of «function.» While Durkheim's arguments on the functions of education remain unproven, they retain the hope, moving forward, of the application of sociological knowledge about the functions for the purposes of educational governance (Durkheim, 1922:51). Later, T. Parsons hypothetically identified four functions of education: academic, distributive, economic and political (Parsons, 1959). But this set of functions can be found attributed to almost every social institution - it does not reflect the specifics of education. Concordant with the hope referenced by Durkheim was the function problem advanced by R. Merton. As Merton stated in his more general theorem, «the social functions of an organization help determine the structure... just as the structure helps determine the effectiveness with which the functions are fulfilled» (Merton, 1968:136). In other words, the organizational structure of a system must be adequate to the given functions, while knowledge of the functions is consequently applicable in organizational and social management. 
The classicists of the sociology of education did not describe the method to identify functions. They used to postulate certain functions without regard to the criteria or methods to be utilised in the search of functions, and this lack of substantiation persists to this day. Well-known sets of functions (those given by Durkheim, Parsons, Merton or other contemporary authors) are cited speculatively without any theoretical justification, and only sporadically accompanied with some empirical illustrations.

The function problem is, in fact, the theoretical backbone of the sociology of education. This certainly does not exclude other planes for the analysis and theoretical constructs of phenomena occurring in the educational arena, but it is precisely the concept of the institutional functions of education which is capable of encompassing the multiplicity of other constructs (including the microsocial) within the overarching architecture of sociological knowledge, giving it both compatibility and operationality. The stream of education functions (both manifest and latent ones) encompasses all social interactions among actors in the sphere of education. It would be expedient to conduct the sociological study of such interaction in the context of the functions of education, which would make it possible to create a more holistic picture of the life of educational commonalities from the standpoint of the efficacy of their particular education programs or strategies. Proceeding from the concept of functions, researchers can move beyond the interaction between teachers and students traditionally investigated by pedagogy and psychology and move into the other social spheres with which education is connected by virtue of its functions, including, inter alia, economics, social inequality, politics and culture.

The concept of institutional functions plays a methodological, navigational role in the sociology of education, without replacing or substituting for other problems and levels of their investigation. This concept is not limited to the structural level, but reflects the totality of social interactions in education, including those at the micro-level. It can provide impetus to the internal branches of the sociology of education and serve as the basis for the integration of their results into the sociological theory of education.

A detailed version of the functions of education was published about twenty years ago in Russia, without critical response nationally (Osipov, 1998). Hypothetical in nature, it searched for the universal socio-historical features of education. It would be worthwhile to continue the discussion on theoretical backgrounds of the study of the institutional functions of education, the scope of the search for the functions, the boundaries of education's responsibility in society, the criteria of functions and the methods in justifying the functions. It is also important to specify the practical potential of the concept of the functions of education.

The concept of the institutional functions and understanding of the system structure of education are complementing each other (Osipov, 2006:171-211), thus delineating the problem field of the sociology of education and creating a theoretical foundation for its integration and interactions with adjacent research areas (those outside of the domain of education).

\section{The search for functions in the context of social practice}

The reason of our addressing the functions of education lies in determining the scope of the institutional responsibility of education, as well as in arranging a rational organizational structure of education at all of its functional levels - from administering in individual school settings to the state educational governance.

We usually accept that one of the education's institutional functions is its involvement in the reproduction of the occupational and qualification composition of the population. But then one can view as a fundamental misunderstanding the fact that the administrative structures of vocational education (from 
individual colleges to regional committees and the federal ministry) has no internal divisions (departments, units) responsible for this particular function. Such divisions should have systematically keep up studying demands in the employment realm. Russian colleges and universities used to set their admission plans basing on their own corporate interests (which is viewed as their corporacentrism - organisational ignoring the actual needs they are thought to serve to). This regularly led to imbalances in the structure of graduates, whereby half of them now are working at jobs irrelevant to their specialization and one in six is unemployed. The situation was that wrong for decades, while primary and secondary vocational education badly suffered from an acute shortage of applicants.

Heeding this example, the organizational structures of the education system and its local establishments should be built in accordance with the appropriate functions. From here, elaborating the problem of education's functions can call into question certain approaches and criteria of its administration might expose the corporacentrism in the system and its establishments (Osipov, Ivanov, 2004). It could help find a balance between responsibility for fulfilling the functions of education and the countervailing array of financial-economic and legal norms at the state level.

In contemporary sociology, most of interpretations of the functions of education have «frozen» at the level of Durkheim, Parsons and Merton. Mention is usually made of some common functions: socialization, cultural transmission, social control, selection and the attainment of social status (Ballantine, Hammack, 2009). They usually refer in a very general way to the societal mission of schooling, but are limited to the social sphere. In this form, the knowledge of functions is not transmittable into education practice and policy. In Russian sociology, the interest towards institutional functions of education has been lost. Yet it does not entail the practical application of the function knowledge.

Thus, the idea of the functionality of social institutions remains, while the study of the functions of the same institutions continues to linger in the shadows. Yet, there can be no doubt that two phenomena and concepts - social institution and institutional function - share a common fate. These concepts will either be conceptually formed together or fade from scholarly horizons, at which point the social institution as a sociology's fundamental notion will come into question (or just die). If sociology refrains from elaborating the problem of functions as it applies to those social institutions which are administered by the state (education, healthcare, social security, etc.), then these same institutions will be doomed to remaining under bureaucratic control. In Russia, the literature on educational management totally ignores the problem of the functions of education, which helps explain the administrative leapfrogs and frequent revisions in the rules, standards, competencies and reporting (accounting) forms.

And what is the range of phenomena that encompasses the problem of functions? Sociologists usually define education as organized and purposeful (methodical) socialization (Durkheim, 1922). While the criterion of this purposefulness requires its sociological interpretation, it does distinguish education from the multitude of spontaneous socialization processes. Education can be logically divided by the criterion of formal organization into two spheres: manifest (formal) and latent (informal). Formal education is represented with schooling (and various programs) that concludes with the issuance of the respective certificates. Informal education encompasses the socializing influences exerted by family, religion, media, advertising, cinematography, etc. which are subject to sociological study.

The actors, who are methodically included in the processes of socialization, implement certain education programs that meet their own social strategies. A program assumes the objectives and content of 
socialization in a particular area, as well as the respective methods and providers. Methods are frequently highly sophisticated, with an emphasis on special target-audience research and effectiveness metrics, etc. An education program is a systemic substantiation of any purposeful socializing influences - from those emanating from the family or the mass media, which are seemingly routine and spontaneous, to those more long-term and organizationally regimented, as practiced in the instruction of the professions. While the agencies of formal education implement a quasi-synthesis of manifest and latent programs, the programs of informal education are frequently latent, advancing the legitimization of particular values, norms, styles and practices.

Latent education programs promote certain cultural types that are at odds with the aims of manifest programs. Thus, countervailing the officially-declared array of social values and norms (life, health, work, justice, accountability, law-abiding behavior, patriotism and healthy lifestyle, etc.), latent programs, acting according to the principle of the freedom of choice in entertainment and the idea that «whatever is not prohibited is allowed,» advance the opposite values (force, risk, chance, independence, individualism). Unfortunately, this often goes at the expense of the citizenry - the taxpayers. Manifest programs are often designed to overcome the effects of latent ones, thus reflecting hidden institutional conflicts in the society.

The criterion for assigning latent programs to the sphere of education is the fulfillment of the general functions intrinsic to education as social institution. Once these general functions have been identified, it becomes possible to search for the specific functions that distinguish one sector or level of education from the other.

\section{Institutional function in application to education}

The dissonance in defining the functions of education is explained by the fact that the education's social output is often delayed across time and manifested in sweeping results that are resistant to accounting, as well as by the crossover interference (juxtaposition) of a number of discrete functions. The same may be said of the return on manifest and latent education programs (formal and bidden curricular). Theorists would tend to keep off the function problem. Sociologists have made little (if any at all) effort to elaborate approaches to the measurement of functions, restricting themselves to philosophical interpretation in such vague terms like «mission», «social role of schooling», etc. But the very concept of «function» as it applies to the social institution is deserving of elaboration across a whole range of issues: on the correlation between functions and other adjacent phenomena and categories, on the methods for identifying functions, on the stability or variability of functions, and on their specificity as intrinsic to a particular institution.

Some functions of education are not recognized for long by public perception and science at certain intervals of history, at which point those functions fade from the ranks of education system's public tasks. On the other hand, dominant groups and organizations may emphasize certain function in an effort to elevate it to the status of the manifest tasks of education. Thus, the fulfillment of functions is conditioned by the social structure, social ideology and society's dominant groups in economics, politics, social development and culture.

The vocabulary of contemporary sociology insufficiently delineates the adjacent phenomena in the problem under consideration. Clarification of these phenomena and concepts has been partially provided in descriptions of the interrelatedness and disparity of functions, public tasks, social expectations and social requests in the area of education. Institutional function is viewed as a socio-historical universal feature of this institution (Osipov, 2006:212-227, 462-478). Thus, the identification of functions may feature the 
application of historical-comparative methods making it possible to demonstrate the social-historical universality of particular characteristics of education as social institution.

Publications touching on the problem of the education's functions have identified immediate or prospective tasks of education, formulated from the position of a particular sociological or socio-political paradigm, but insufficiently addressed the institutional specifics of education. We shall endeavor to set out those aspects of the function as a category that would be helpful in approaching a clearer theoretical understanding of the phenomenon.

Function is a stable sort of influence that education is exerting on the main spheres of society. Within those spheres, the influence is exerted on their structures, connections and actors. Institutional functions are those socio-historical universal features of education that are resistant to rapid or frequent change. The method for the theoretical delineation of the functions lies in the critical filtration of education' manifestations from ideological stamps, situational and transient characteristics in the sphere of education. The search for functions rests on comparative and socio-historical analysis, and this method - in combination with the criterion of empirical operationality - has made it possible to develop a fuller, albeit not exhaustive, version of the institutional functions of education. The weakness of this proposed concept remains the dearth of experience in its empirical and socio-practical approbation.

\section{Criteria of function}

In defining the functions of education as a social institution and of individual organizations as its discrete elements, it would be prudent to set the appropriate boundaries so as to avoid arriving at theoretically and practically unproductive results, confusing adjacent social phenomena in education. This is particularly important at the initial stage of formulating the problem of institutional functions, when a preliminary, theoretical (logical, hypothetical) search is conducted and fragmentary argumentation is accumulated. This search and argumentation have thus far not been elevated to the sort of comprehensive investigations that would make it possible to measure functional processes and evaluate the substantiation of theoretical discourse in this problem area.

Firstly, all of the elements of the function model of education as an institution must be compatible with the categorical apparatus of sociology, and moreover - serve as a constructive basis for empiricallymeasureable indicators of the function of education encompassing in their totality all of the realities of this particular social institution. Important in this respect is the general-sociological definition (conceptual operationalization) of education as an institution (Osipov, 2006:311-313). This general definition in no way excludes other, more specialized definitions of education which may be necessary in revealing, by way of intensive operationalization and empirical interpretation, the specific properties of this social institution - for example, from the standpoint of the theory of cultural-linguistic codes or the labeling theory. However, the conceptual terminological compatibility as a methodological requirement for the search of functions within the scope of the social sciences remains.

Secondly, the content of formulations of the institutional functions of education must reflect its most stable characteristics, associated with its socio-historical universals. This makes it possible to distinguish functions ensuring the integrity of society and its reproduction from fleeting and short-term social requests and, consequently, imbalances in sociological constructions of institutions. 
It's important to distinguish logically the two sides of the problem from one another. Function, as a logically - and empirically - definable sort of stable connection ensuring the integrity of society and characterized with socio-historical universality. Function shows up always and everywhere in the sphere of education. Function is an objective parameter of education allowing for an evaluation of the conditions of education as asocial institution, its dynamics, scope and impact on society as a social, socio-cultural system. Functioning is a process unfolding within the bounds of a particular kind of stable connection. The content of this process may change in the same sense as the content of socialization processes, in which a wide range of values, norms and behavioral patterns are reproduced.

Proceeding from this distinction, one of institutional functions of education is the organized reproduction, whether at the group, community or societal level, of certain types of culture. But in different socio-historical situations, different types of culture are subject to reproduction - national, peasant, religious, proletarian, bourgeois, professional, etc. This in no way leads to the changeability of functions, since what changes is the content of functioning - but not the sort of stable influence (that is, function).

Using a well-known analogy, we note that under normal conditions, an individual bodily organ (digestive tract, eye, nervous system, etc.) as a system fulfills its own (the same stable) functions, irrespective of the content of the functioning process (food ingredients, lighting conditions, nature of external or internal irritants), thus supporting the wholeness of body. In physiology, this distinction makes it possible to identify the functions of each of the organs by distinguishing them from the various situational manifestations of the content of functioning (the digested food, conditions, influences). That allows medicine to monitor the organ's status according to its stable parameters (functions), cure it (that is, overcome dysfunction), and thereby maintain conditions that are favorable for the body as a whole.

In our view, it is essential to clarify the categorical apparatus used in studying the functions of institutions, including education. Otherwise, the classical terms and concepts of sociology with which the theoretical constructs of social institutions and sociology of education are associated (just as other mid-level theories) will remain shaky elements of social theories.

Thirdly, formulations of institutional functions must serve as the specific characteristic of this institution, and be minimally superimposed on the characteristics of other institutions. Otherwise, the concepts of other institutions will begin merging and converging - first and foremost through the convergence of the characteristics of their functions. This criterion is rooted in a sociological concept that defines the social institution as a relatively stable assemblage of norms and organizations regulating the satisfaction of a particular sphere of societal and human needs. This criterion is associated with the development not only of the sociology of education, but also of other mid-level sociological theories.

This criterion upsets the usual notions of the institution of education, but meeting this criterion is still possible. Thus, the aspect of the institutional functions of education from the standpoint of social reproduction (of human, of culture) could result in the recognition that reproduction occurs through the efforts of all of the main social institutions. The reproduction paradigm states that all institutions, in one way or another, fulfill certain, the same range of functions: they all regulate the needs of individuals and groups, conduct socialization, exercise social control, differentiate communities and reproduce certain elements of culture, thereby ensuring the integration of society and maintaining its wholeness as a system. Admitting this vein of functions could lead to the conclusion that in the functional sense, all social institutions sometimes duplicate one another in fulfilling their respective functions in the socium. 
In that case, the assertion that one of the institutional functions of education is reproduction of culture fails to express the specifics of this institution, since the reproduction of culture in society is supported regularly by the state, the economy with its organization and division of labor, family and religion. But sociology would need to distinguish stable parameters expressing the education's institutional specifics. This makes it possible to develop the concept of social institution, as well as its specific efficacy criterion and the optimal model of its organisational structure, in view of its own functions for the purposes of educational management.

From here, formulations of institutional functions of education must minimally superimpose (overlap) on the functional characteristics of other institutions. However, to avoid mutual interference, overlapping of formulations functions of different institutions completely will hardly be possible. This is due, firstly, to the fact that social life exhibits the complementarity of role structures and institutions as normative complexes regulating interactions of people. Secondly, the theoretical study of institutional functions has thus far failed to achieve a clear distinction between structures and processes. Thus, the socialization processes reveal partial interference or conflict of functions on the part of the family, religion and school. From here, the absolute delineation of institutional functions is unachievable, but this does not discard the task of formulating a specific concept of the functions of a particular institution, including education.

Fourthly, the concept of the education's functions should not suffer from excessive conciseness. Formulations of specific functions must be clearly operational within the system of sociological terminology, but most importantly - be open to empirical interpretation. This would make it possible for the theoretical constructs developed in the sociology of education to approach empirical measurements, applied research, and practical solutions based on the concept of the institutional functions of education.

These are the general theoretical concerns to take into consideration to approach a clearer sociological vision of the place and role of the institution of education in society. We believe that sociologists can accept the importance of such a consideration when they design their theoretical and/or empirical research on education, when they feel concern about how their future research results would contribute to developing a sociological theory of education, improving educational policy. We also dare hope that the proposed theoretical model of education functions can be corrected and developed in the future. Then, the sociology of education would begin approaching the level of knowledge at which, according to R. Merton, the interpretation of functions serves to determine the optimal structure of its organization and efficacy, and the sociology of education ceases to play only a role of delayed/late criticism of education policy. For now, the general impression is that new areas of thematic and conceptual advancements are emerging within the sociology of education, while its basic constructs and concepts remain foundationally unsubstantiated. Given the obscurity of these basic structures, overcoming the theoretical crisis in contemporary sociology, including in its mid-level theoretical areas, would seem elusive.

Interaction between the education system and other institutions is bilateral in nature. The system itself reacts to the dynamics of other institutions, altering its internal structure or content according to changing conditions. This reaction most often is lagging behind, as the classics of sociology noted back in their day. Now let us discuss a version of the institutional functions of education in application to the main spheres of society's life: economic, social, cultural and political. 


\section{Functions of education in the economic sphere}

a) Formation of the structure of workforce. This function appears locally, nationally and globally in both its quantitative and qualitative aspects. In the quantitative aspect, the education system is responsible for the formation of occupation-qualification proportions in the workforce. In practice, however, this influence is almost never optimal. Due to its institutional and organizational inertia or administrative errors, the education system leads to the overproduction or underproduction of individual professional corps. This results in a situation where certain occupational groups experience an influx of people without the appropriate preparation, and workplace training becomes widespread (without the appropriate theoretical knowledge and creative skills). Both, overproduction and underproduction has a negative impact on the vocational structure of the population, leading to an erosion of professional cultures.

The qualitative side of this function ensures the formation of the productive qualities of workers. It is primarily conducted by vocational-education institutions, but also in the framework of labor activity and general education. According to statistics, a worker's labor productivity and innovation activity increases as his educational attainment level expands.

b) Formation of the public's consumer standards. Education's influence on the economy concerns not just the production, but also the consumption of goods (information, cultural values, financial and natural resources, etc.). This function has always been inherent to education - suffice it to recall the biblical commandments about the moderation of consumption, and this function also largely determines the content of informal education in the family and neighborhood community.

The education system can instill rational standards to social, material and spiritual needs. In this way, it contributes to the emergence of a resource-saving economy and a human-friendly environment. But in the market economy this function of education is opposed to the interests of business, as embodied in commercial advertising with its hidden message to «consume more!» This advertising intensifies consumerism - a strain of the mass culture in which consumption serves as a criterion of progress. An example of the formation of consumer standards is the introduction of academic courses on environmental protection, social ecology, healthy eating, personal hygiene, public health and safety, civil and consumer rights, etc.

c) Attracting economic resources for the purposes of the education system. The education system is a major consumer of public resources. It attracts and expends the economic (material, financial, etc.) resources without which its functioning is just impossible. The sources of these resources vary largely, ranging from the state budget to private investments and paid services, but these sources point to the dependence of education on other institutions and organizations.

The function of attracting economic resources explains a lot in the content and forms of education. Reliance on the state budget intensifies unification, while the orientation towards business circles strengthens the autonomy of education in terms of its content and organization. As schools shift from federal state to local (municipal) budgets, the development of the regional and local component in academic content has been activated.

Money-making by educational settings has become a special feature of this function. This feature reflects a liberal-market orientation towards education as a service which, together with the expansion of the right to choose leads to the segmentation (organizational stratification) within the system of education, to the weakening of its mission of forming the moral character of the next generations and the social 
integration of society. The commercialization of education is generally frowned upon by sociologists and educators, but remains among the performance indicators of its organization, as applied by the top management of the education system.

d) Internal distribution of economic resources. As represented by its various management bodies at all levels (federal ministry, regional departments, school administrations, etc.), the education system distributes the funds it attracts among its many regions, internal subsystems, establishments, organizational subdivisions and jobs. As a result, resources are allocated for different sectors - including those outside the educational process itself (support for commercial structures, research and ranking agencies, security services, social and health protection services for students and teachers, advertising, etc.).

This distribution is capable of intensifying social inequality when some subsystems of education can be lacking the required resources. Thus, the transmission of kindergartens in Russia to the municipal budget may reduce their ability to maintain a high level of preschool education. Children deprived of preschool training are frequently incapable of subsequently coping with primary school programs. Social consequences of such practices of the resource distribution turn out to be of tremendous importance to society as a whole.

The education system is also capable of modifying the internal criteria for stimulating the performance of students and staff, thereby changing their socio-economic statuses.

The distribution of economic resources is predicated on the nature of the social organization of educational establishments or their networks. The social predicate of this distribution turns out to be even more substantial than the economic predicate - after all, economic criteria often lack direct application in the sphere of education. Pushed to the forefront are those criteria that reflect the normative outcome of consensus among certain professional groups inside education or around it. At times, the education system undertakes this distribution in defiance of all common sense. For example, the Soviet system of teachers training overproduced teachers, which in turn stunted growth in teacher incomes, the improving teachers' housing conditions, and the technical equipping of schools. Another example of distribution contrary to the interests of the education system is the annual generous allocation by the RF Government of billions in budgetary subsidies for a select few of the leading universities with the aim of elevating their positions in the global rankings and foreign citation indices. This kind of «selective» support for rich universities does nothing to address the financial plight of the majority of universities, but hints at the lobbying of foreign business interests (ranking agencies, registration-publication systems, etc.).

From the standpoint of sociology, this raises the question of the social mechanisms behind the distribution of economic resources in the education system. What status groups within the education system - or beyond it - have a decisive influence on these mechanisms? Such questions must be focal to the sociological understanding of emerging trends in the development of the education system.

\section{Functions of education in the social sphere}

a) Homogenization of society through the organized socialization of individuals. Durkheim was the first to mention the function of homogenization. In a society undergoing social and cultural differentiation, this function ensures the reproduction of a common system of social norms and substantive knowledge with the organizational support of individual educational establishments and educational communities. 
b) Formation and reproduction of educational communities. The sphere of education is regularly forming and reproducing educational communities, within which individuals are connected with each other by their mutual participation in educational (learning, instructional, managerial) processes and their particular value-conscious attitude towards education and knowledge. These communities spring up inside and around the domain of education. They are exemplified by various professional, parental, student and other groups (including mixed ones) participating directly or indirectly in the performance, maintenance or management of educational activity. These groups and communities occupy their own place in the social structure of society, exerting a real influence on the functioning of education through the various channels of social mandates and support for particular education strategies (trajectories).

c) Activation of social mobility - a perceptible function of education. It manifests itself to the extent that in a system of inequality, achievable statuses depend largely on formal educational attainments of individuals.

Education has evolved to become one of the mass social channels and social elevators (lifts) of social mobility, leading mostly to more sophisticated types of labor, higher incomes and greater prestige. But the actual start of this process was marked by the introduction of informal (as verbal recommendations) and formal certification in different types of jobs and the emergence of the corresponding types of vocational training - from a child doing an apprenticeship with a master tradesman to cutting-edge forms of education, including contemporary IT-based distance education.

Social movement through the channels and elevators of education is the main prerequisite for a more open social-class structure, for society's movement towards more egalitarian values and norms, towards the alleviation or even erasure of painful disparities in the social conditions of different strata and groups. That was the real impact of education in the USSR, when two-thirds of the augmentation of intellectuallabor groups were achieved due to upward social mobility (from the bottom of the social pyramid, so from the peasantry and working class).

Yet, it is important not to overemphasize the upward mobility associated with education. In today's Russia, a university graduate working as a provincial teacher or physician earns a salary on par with the subsistence minimum, which does not allow for economic independence. A PhD qualification and employment as a university professor signifies nothing more than a very heavy burden of teaching load and approximation with the average income level in the regional economy. This is associated with the weakness of state control over the economic disparities and stratification of the population. RAS academician M.K. Gorshkov, speaking at the Fifth All-Russian Sociology Congress (October 2016), reported that while the decimal coefficient of economic inequality in Russia officially stands at 13 , it actually exceeds 20 and approaches 40 in metropolitan areas.

Education also determines the mobility of individuals within the demographic structure of the population (settlement, family, marital structures).

d) Social selection. In the education system, students are formally and informally divided by indicators deemed significant to the system, and these kinds of divisions are often combined (streaming, tracking). Informal division may show up in localization of students inside classroom, in uneven amount of attention and encouragement provided on the part of the teacher, etc. Selection becomes obvious according to empirical research. 
The formal basis for tracking is provided by the nature and level of the intellectual capabilities exhibited by the child in the educational process. These capabilities, in turn, are identified through the tests, but assignment to particular streams may also take into consideration the personal recommendations by educators, relatives or sponsors. Academic tests always contain certain cultural context, and the student's ability to cope with the test depends on the distance between the school culture (professional cognitive culture) and the cultural traits of student's primary socialization environment. The most advantageous roles, the longest attention and the greatest encouragement usually go to those students who satisfy the requirements of the dominant (school) culture. Cultural differences often have an impact on how quickly and fully the abilities of students are developed. In the more prestigious forms of education, payment for education or accommodation is becoming an important condition.

e) Reproduction of social groups and strata, affiliation with which is conditioned by educational attainments. The system of formal education supports the development on the part of individuals of skills and aptitudes corresponding to particular social and professional functions and roles. This function was demonstrated in previous epochs by informal evidences, and now - by credentials as a condition of occupying certain positions in the economy and social stratification, of ascending to certain social groups and strata, as proved by R. Collins in his The Credential Society.

f) Substituting for parents, providing social support for students, most of whom are children or adolescents, has historically been and continues to be a function of education. For centuries, schooling represented the continuation of the traditional care provided by the older for the younger, but is now associated with society's orientation towards the creation of early access to education and a comfortable learning environment. This support is provided over the extended period of time spent within the walls of an educational setting, where specialized organizational and role structures reminiscent of the home environment are recreated - meals, communications and recreation, bedding, medical care, play areas and safe outdoor grounds. In this function, education reproduces the role differentiation of the sexes and genders typical of the family.

\section{Functions of education in the sphere of culture}

Speaking of the functions of education with respect to culture, many philosophers and sociologists habitually refer to the transmission of culture to the younger generation, or of the reproduction of culture. Yet, this assertion is only valid in the global context. Even in the best-case scenario, an individual gains from the education system only a fraction of the national culture and minimal insight into the world culture. Schooling gives an individual the basic elements of a society's core culture, and university - the basic elements of professional culture. The social conditions of the transmission of culture constitute the central problematics of the sociology of education. But education also reproduces the entire specter of cultural differences between different social groups and strata.

a) The reproduction of particular social types of culture (ethnic, historical, local, regional, group, etc.) and their components - systems of values, norms and practices - is the leading function of education. Yet education reproduces far not all types of culture, but only those supported by the leading social request. The remaining types of culture, including minority cultures, are not included in reproduced cultural content.

School increasingly transmutes intellectual and professional experience into formalized constructs, allowing it to be systematized, configured, scientifically analyzed, accumulated and transmitted. The edu- 
cation system reduces the amount of time spent on mastering certain types of culture - it encourages a more open social structure, a broader exchange of culture locally, nationally and internationally.

One of the manifestations of this function is the reproduction of school subculture (college, academic, etc.).

Educational communities, unlike others, are mostly mono-aged (each consisting of individuals of similar age). The cultural conflict between the generations is likely associated with this particularity. School, encompassing youth, is the breeding ground of a subculture in which the core value has become the continuous process of updating knowledge, renewing intellect and skills. This renewal is less typical in other cultural environments. The daily activity of the student, his/her status and formal evaluation in the microenvironment of the school depend completely on his/her success in renewing intellect and skills. This renewal (increasing complexity/qualification of educational exercises from grade to grade with each passing academic year) becomes the overarching principle of the school culture. The value of this renewal is not typical of most older people, and this difference is likely the latent basis for the intergenerational cultural contradictions observed in society.

b) Innovations in the sphere of culture. Sociologists from the functionalist paradigm were the first to point to the fact that education drives innovations in the sphere of culture. This function complements the function of the reproduction of socio-cultural types. In the broader socio-historical sense, education supports cultural innovations, but in specific historical situations, education also counteracts certain cultural innovations.

This function has two interconnected prerequisites - cultural and social. From the standpoint of the former, the public education system relays but a fraction of the innovations achieved in sciences, arts, law, religions and other institutions. To this end, it sorts and wraps these selected innovations (norms, information, technologies, values, etc.) in the form of educational (cognitive) materials. The selectivity with which education sorts out innovations points to the social nature of the organization of education and its interconnectedness with other institutions and social groups. As a rule, the innovations that receive support are those lying in the mainstream of the core culture and not posing a danger to the overall integrity of this social organization (or the stability of its management structure). We here, of course, mostly consider the public schooling programs. There can be quite opposite programs of civil education, radical activists training, which usually precede all sorts of modern revolutions (like the «Arab Spring», «the Rose Revolution», the «Dignity Revolution», etc.) and are sponsored from abroad, bringing to the destruction of national states and the split of societies.

c) Formation and reproduction of public intellect (mindsets, disciplines and social technologies of intellectual activity). Since its inception, the public education system has been transforming into a multidisciplinary complex whose purpose is not merely the transfer of knowledge, but also the reproduction of public intellect.

Substantive knowledge appears not in the form of individual facts, but takes the shape of relatively independent cognitive sets (schooling subjects, scientific disciplines, professional standards, etc.). Precisely this function could play a key role in the pace of civilizational progress in the future, and has already transformed into one of the factors of international cooperation and competition. Confirmation of this fact are the attempts on the part of states and international organizations to establish conceptual control over education systems in different regions of the world. In this case, education and public intellect of a 
recipient country (so, a receiver of educational technologies) fall into dependence of the donor country or donor organization (so, developer and distributor of educational technologies). This dependence is possibly even more influential than technological dependence in industry, insofar as it makes profound changes to the elemental base of the recipient's public intellect and guarantees the primacy of the donor. Martin Carnoy described it in his Education as Cultural Imperialism.

But even countries with longstanding traditions in their own education systems, like Russia, can find themselves in a position of intellectual dependence. This becomes more likely when the state and society lose conceptual control over the development of education, at the same time as a large portion of the political and intellectual elite ignore national interests.

\section{Functions of education in the socio-political sphere}

The formation of the civic identities of individuals comprises one of the priority interests of the state, society and communities. An essential component of content in any education system consists of the values and norms of legal and political conduct in society and the state. This component comprises law courses, Constitution lessons, but is most commonly associated with the political culture of dominant groups. Thus, the education system fulfills functions in the socio-political sphere.

a) Cultivating acceptable legal and political values and norms, methods of participating in political life among educational communities. This function is typical of both formal and informal education. While the education system sometimes lends approval to certain alternative types of culture or cultural styles, there are virtually no examples of the institution of education condoning legal or socio-political deviations. Due to the importance of this function, education often is viewed an instrument of political supremacy (Gramsci, Freire, Apple, etc.). It is not by coincidence that each newly-formed political regime endeavors to establish control over the content of education or creates its own new school system. Recognition of this function leads to the ideologization of schooling. In this sense, school also fulfills another function with similar content.

b) Encouragement of law-abiding legal and political behavior, reproduction of state (leading) ideology. Social groups that are carriers of alternative political and legal ideologies attempt either to establish an alternative school, or to add their own sets of legal and political values to existing education content. From here, the school becomes a field for social movements and political battles, as the legal consciousness of the masses is preconditioning the stability of political regime.

The education system is not sterile in the ideological sense. It is always subject to the ideological control exerted by dominant groups. In the USSR, this function appeared publicly with ubiquitous school - or college-based Communist Party committees. Today it operates in latent forms, in which most of social sciences and humanities in public education programs are following the values of liberalism, individualism and globalism.

This function aims at the legal and organizational integration of society, that is - at maintaining the integrity of the system as a whole.

c) Encouragement of patriotism becomes a function of education in the context of each national state. Within the content of education, it is transmitted by the citizen's code and expresses the expectations of the state. This function serves as a precondition for the preservation of any nationalstate community in the unstable geopolitical environment. Moreover, national culture leaves a mark 
on the content of education, highlighting within it the totality of values that underscore the specific interests of its ethnos. The encouragement of patriotism is a feature of most state systems of public education.

This version of the functions of education aims at application of the four criteria for defining institutional functions substantiated above. It certainly makes no claims of being complete, and is subject to both theoretical criticism and empirical approbation. This version intends to direct the attention of educational sociologists towards a problem, which, in our view, is creating clearer theoretical architecture for the sociology of education, and with it, opportunities for the integration therein of new thematic areas and empirical studies, as well as social practical outcomes in the interests of the education system, society and the state.

\section{References}

Antikainen, Ari et al., (2011): “Contemporary Themes in the Sociology of Education". International Journal of Contemporary Sociology, 48 (1), 117-147.

Ballantine, Jeanne H. and Hammack, Floyd M. (2009). The sociology of education: A systematic analysis (6 ${ }^{\text {th }}$ ed.). Upper Saddle River: Prentice Hall.

Durkheim, Émile (1922). Education et sociologie. Paris: Presses Universitaires de France.

Ivanov, S. V. and Osipov, Alexander M. (2004): “The university as regional corporation”. Sotsiologicheskie issledovaniya [Sociological studies], 11, 162-172.

Merton Robert King (1968). Social Theory and Social Structure. Enlarged edition. New York: Free Press.

Osipov, Alexander M. (1998). Society and education. Lectures on the sociology of education. Novgorod: NovSU.

Osipov, Alexander M. (2006). Sociology of education: Essays on theory. Rostov-on-Don: Phoenix.

Osipov, Alexander M.; Ivanova, Viktoria and Dobrenkov, Vladimir (2013): “Global Sociology of Education: General Perspectives. Monograph Supplement to 'Sociological Studies"'. Journal of the Russian Academy of Science. Veliky Novgorod: Yaroslav-the-Wise Novgorod State University.

Osipov, Alexander M. (ed.) (2014). Sociology of Education Abroad. Veliky Novgorod: NovSU.

Parsons, Talcott (1959): “The school class as a social system”. Harvard Educational Review, 29 (4), 297-318.

\section{Nota biográfica}

Alexander Osipov es Doctor en Ciencias Sociales; Yaroslav-the-Wise Novgorod State University (NovSU). Profesor en el Departamento de Sociología y Educación Bilingüe. Miembro del consejo editorial de la revista Education and Society; co-director del comité de investigación (RC) de Sociología de la Educación. Entre sus líneas de investigación, destacan: sociología de la educación, juventud, salud pública. Entre sus recientes publicaciones, cabe mencionar: Global Sociology of Education. General Perspectives (coeditado con Viktoria Ivanova y Vladimir Dobrenkov), Veliy Novgorod: Moscú, 2013. 